\title{
Tecnologias Digitais nos Processos de Ensino e Aprendizagem dos Conteúdos Escolares: Compreensão dos(as) Licenciandos(as) da Disciplina Tecnodocência
}

\author{
Deyse Mara Romualdo Soares1, Gabriela Teles2, Robson Carlos Loureiro3, \\ Luciana de Lima3, Luís Paulo Leopoldo Mercado1
}

1 Programa de Pós-Graduação em Educação - Universidade Federal de Alagoas

2 Pedagogia - Universidade Federal do Ceará

3 Instituto Universidade Virtual - Universidade Federal do Ceará

1 Programa de Pós-Graduação em Educação - Universidade Federal de Alagoas

\{deysemarasoares, gabiteles2s.as\}@gmail.com, \{robson,

luciana\} @virtual.ufc.br, luispaulomercado@gmail.com

\begin{abstract}
In the current scenario of TDICs in society challenge pedagogical practices, initial teacher education demanding new approaches and teaching methods. This article aims to describes the perspective of undergraduates, from the optional subject Technoteaching offered by the Federal University of Ceará (UFC), in the period of 2018.2, about how the TDICs are presented in the teaching-learning process of the contents that they intend to work in his teaching profession. It is based on the Case Study as a methodology and is subdivided into three stages: data planning, data collection and analysis. It is observed that they have changed their perspective by reflecting more critically on the integration of TDICs. It is considered important to reflect on the integration of TDICs in the initial training of graduates.
\end{abstract}

Resumo. No cenário atual das TDICs na sociedade desafiam práticas pedagógicas, a formação inicial de professores demandando novas abordagens e métodos de ensino. Este artigo tem o objetivo descrever a perspectiva dos alunos de cursos de Licenciatura, da disciplina optativa Tecnodocência ofertada pela Universidade Federal do Ceará (UFC), no período de 2018.2, acerca de como as tecnologias digitais de informação e comunicação (TDICs) estão presentes no processo de ensino-aprendizagem dos conteúdos que pretendem trabalhar na sua profissão docente. Baseia-se no estudo de caso como metodologia e subdivide-se em três etapas: planejamento, coleta e análise de dados. Observa-se que modificaram sua perspectiva, refletindo mais criticamente sobre a integração das TDICs.

\section{Introdução}

A sociedade está mudando nas suas formas de se organizar, de produzir, de comercializar, de ensinar e de aprender. Tais transformações estão vinculadas ao 
aperfeiçoamento, sofisticação e popularização da internet e das TDICs que ajudaram a causar profundas alterações em praticamente todos os setores da sociedade, modificando as relações econômicas, políticas e sociais, e também a capacidade de obter e transmitir informações [Coll e Monereo 2010]. Assim, com o desenvolvimento tecnológico a sociedade se encontra, de acordo com Castells (2000, p. 60), diante de "um novo paradigma tecnológico".

Esse cenário atual das TDICs institui práticas sociocomunicacionais que desafiam práticas pedagógicas, a formação inicial de futuros profissionais, de professores da educação básica e universitária, demandando novas abordagens e métodos de ensino para se manter a motivação do aluno além de se oferecer possibilidades de professores e alunos serem autores de conhecimentos [Mercado 2014].

A justificativa principal para esta pesquisa se dá pela reflexão acerca dos cursos de Licenciatura como formação para a prática docente na sociedade contemporânea, definida como Sociedade da Informação por Coll e Monereo (2010) na qual as TDICs estão presentes na vida cotidiana dos alunos, e as discussões sobre o uso destas tecnologias na ação docente, mostram, de acordo com Costa (2010), que as discussões e o uso das TDICs nos processos de ensino e aprendizagem não recebem atenção especial pelas instituições de ensino superior (IES) em seus cursos de formação inicial de professores.

No contexto atual, torna-se relevante refletir sobre a formação dos alunos, em como compreendem o uso das TDICs integradas à sua área de formação, à qual, possível e brevemente, torná-los-á professores na Sociedade da Informação.

Diante desse contexto, a pesquisa buscou responder a seguinte questão: como os(as) licenciandos(as), no processo de formação inicial, pensam de que forma as TDICs estão presentes no processo de ensino-aprendizagem dos conteúdos com que pretendem trabalhar na escola? A pesquisa tem como objetivo descrever a perspectiva dos alunos de cursos de Licenciatura, da disciplina optativa Tecnodocência, ofertada pela Universidade Federal do Ceará (UFC), no período de 2018.2, sua compreensão de como as TDICs estão presentes no processo de ensino-aprendizagem dos conteúdos que pretendem trabalhar em sala de aula na sua profissão docente. Utilizou-se, para este fim, o estudo de caso como metodologia e a triangulação de dados como técnica de análise de dados.

\section{As TDICs nos cursos de Licenciatura}

As novas formas de comunicação realizadas mais rapidamente levam o campo da educação a enfrentar novos desafios decorrentes da necessidade e do desejo de integrar as tecnologias às práticas educativas [Almeida 2010]. Esses desafios apontam para as dificuldades existentes de implementar usos educacionais das TDICs em todos os níveis do sistema educacional, da educação fundamental à superior, que realmente representem uma inovação nos métodos de ensino e uma melhoria dos processos e resultados do aprendizado [Coll e Monereo 2010].

Nesse sentido, um dos desafios da incorporação das TDICs na educação tem sido compreendê-las como conteúdos curriculares, como objeto de ensino e aprendizagem, e incorporá-las no currículo [Coll et al, 2010], principalmente universitário, porquanto, os profissionais lançados no mercado de trabalho mostram-se despreparados para a atuação em sala de aula, e é na formação inicial que visa habituar os(as) licenciandos(as) à prática profissional como professores e fazer deles práticos reflexivos [Tardif 2002]. Assim, pressiona-se as IES por mudanças nas relações, 
envolvendo ensino e aprendizagem nos cursos de Licenciatura, pois estas assumem um papel preponderante na formação de profissionais mais adequados ao mercado de trabalho [Ramos et al 2012].

Diante do ritmo de mudanças e as especificidades da sociedade tecnológica contemporânea, o processo educacional realizado nas IES precisa ser restruturado em todas as suas instâncias. Conforme Kenski (2013, p;13), os próprios currículos dos cursos em todas as áreas de conhecimento já não correspondem às expectativas da sociedade para a ação, a reflexão e a formação, e "os jovens recém-formados, egressos de IES renomadas, precisam passear por cursos de capacitação para iniciar atividades em diferenciados espaços de atuação".

Em seus estudos sobre a formação de licenciandos(as), Lima (2014, p.37) afirma que a formação inicial propicia ao licenciando(a) "o desenvolvimento de caráter investigativo, capaz de integrar os aspectos teóricos e práticos, ao observar, estudar e compreender a docência”. Nesse sentido, a formação inicial de professores que não acompanhar as mudanças expostas pela entrada das TDICs nos processos formativos estará em descompasso com a realidade contemporânea, ou seja, estará formando professores em defasagem com as culturas juvenis, as necessidades e as demandas sociais de hoje.

Desse modo, é importante que os(as) licenciandos(as) tenham conhecimento sobre o uso das TDICs e os métodos de como usar seus recursos em sala de aula nesse processo de formação, porquanto, os cursos de formação inicial têm a responsabilidade de garantir aos futuros professores a exploração e a reflexão sobre as TDICs de forma que tenham condições de buscar novos caminhos e possibilidades para inseri-las e utilizá-las em suas aulas, tendo claro quando, como e por que fazer esse uso [Lima 2014].

\section{Metodologia}

A pesquisa de caráter qualitativo utiliza como metodologia o Estudo de Caso. Considerando-se o contexto real de licenciandos(as) da UFC, investiga o fenômeno contemporâneo. Valoriza a expressão espontânea do pensamento dos sujeitos investigados e não controla os eventos comportamentais. Foram utilizadas fontes de evidências diretas na compreensão dos fenômenos estudados [Yin 2010].

Os sujeitos da pesquisa foram consultados mediante a aplicação do Termo de Consentimento Livre e Esclarecido (TCLE) com a pesquisa aprovada pelo Comitê de Ética em Pesquisa da UFC. Foram utilizados os dados apenas dos que consentiram em participar da investigação.

A unidade de análise correspondeu a dezesseis (16) alunos de Licenciatura, cursando a disciplina Tecnodocência, ofertada pela UFC, no período 2018.2, os quais responderam a dois questionários para coleta de dados. A escolha foi feita devido serem alunos(as) em formação inicial para, possível e futuramente, atuarem como professores. Desse cenário destacam-se os seguintes aspectos: $56,3 \%$ são do gênero feminino; $62,5 \%$ cursam do sexto ao décimo semestres; sobre as áreas às quais tais licenciandos(as) estão vinculados, observa-se a presença dos seguintes cursos: Ciências Biológicas (43,8\%), Letras $(25,0 \%)$, Pedagogia $(6,3 \%)$, Física $(6,3 \%)$, Ciências da Computação $(6,3 \%)$, Geografia (6,3\%), e Música (6,3\%).

A Tecnodocência visa integrar os conteúdos teóricos às atividades práticas da docência com o desenvolvimento de planejamentos e materiais autorias digitais 
educacionais (MADE) integrados às TDICs, bem como a articulação de aplicação dos conhecimentos em sala de aula de escola pública com alunos da Educação Básica. As propostas de aula desenvolvidas apresentam características interdisciplinares integradas às TDICs com dois ou mais cursistas de áreas diferentes atuando concomitantemente em sala de aula. É ofertada semestralmente para alunos da UFC.

A pesquisa foi concebida em três etapas: planejamento, coleta e análise de dados. Na primeira etapa, baseada na pesquisa bibliográfica, realizou-se um estudo em artigo, dissertações e livros, sobre as categorias que compõem a pesquisa: TDICs, uso das TDICs em sala de aula, TDICs integradas aos conteúdos curriculares. A base teórica ancora-se nos estudos de Coll e Monereo (2010), Kenski (2012, 2013) e Lima (2014).

A segunda etapa deu-se por meio do acesso aos arquivos da Tecnodocência no Google Drive, em que constavam dois questionários com as respostas dos(as) licenciandos(as), disponibilizados através de formulário: o primeiro questionário, de sondagem, disponibilizado logo no início da disciplina; o segundo questionário, o de autoavaliação, disponibilizado no momento em que já haviam vivenciado as aulas da disciplina.

Utilizou-se o questionário de sondagem para perscrutar os conhecimentos prévios dos(as) licenciandos(as), a respeito da seguinte questão: Em sua opinião, de que forma as TDICs estão presentes no processo de ensino, aprendizagem e avaliação dos conteúdos que você pretende trabalhar na escola? Utilizou-se do questionário de autoavaliação para sondar os conhecimentos adquiridos após a disciplina para a questão de análise: Em sua opinião, de que forma as TDICs estão presentes no processo de ensino-aprendizagem dos conteúdos que você pretende trabalhar na escola?.

A terceira etapa consistiu na análise das respostas dos(as) licenciandos(as) tendo como foco sua compreensão sobre as TDICs e sua integração nos conteúdos a serem ensinados em sala de aula, verificando de que modo e sob qual perspectiva de aprendizagem os alunos fundamentaram sua compreensão de ensino de conteúdos mediados pelas TDICs, tendo-se, com base em Stake (2005), uma triangulação de dados como estratégia que assegure uma compreensão em profundidade do fenômeno investigado. Aplicou-se a triangulação entre a questão analisada no questionário de sondagem, no questionário de autoavaliação e a pesquisa bibliográfica das categorias que compõem o estudo.

\section{Resultados e Discussões}

Para preservação da identidade dos sujeitos de pesquisa são utilizadas a letras L seguido do número indo-arábico para a representação de suas respostas escritas. Os questionários foram analisados, comparados e aplicou-se a triangulação de dados com o referencial teórico que compõem as categorias de estudo.

\subsection{Questionário de Sondagem}

No que se refere ao questionário de sondagem, constata-se que tiraram o foco em responder em como eles utilizariam as TDICs em suas aulas, integrando-as em sua prática docente, e se detiveram em responder sobre como essas tecnologias estão presentes na escola, as ferramentas e recursos digitais disponíveis, sem integrá-los aos conteúdos curriculares que podem ser trabalhados dentro de suas áreas de formação. 
Quanto ao uso das TDICs presentes no processo de ensino e aprendizagem, alguns(mas) licenciandos(as) associaram à transmissão de informação: "Elas estão presentes na distribuição de informações" (L4); "a facilitação de acesso à informação, as diferentes formas de transmissão de conhecimento" (L8); "No ensino as TDICs espalham o conhecimento para os alunos que recebem informações dos conteúdos"(L10). Outros(as), ainda, associaram ao uso de ferramentas e recursos digitais, compreendidas como forma de auxílio, mas sem descrever como integrá-las a algum conteúdo específico a ser trabalhado em sala de aula: "pode ser auxiliado por programas, app e ferramentas que facilitem a aprendizagem, como jogos" (L13); "estão presentes como forma de apoio" (L5); "Na escola, usam projetor para passar slides e passam trechos de filmes" (L12).

Coll e Monereo (2010) enfatizam que um professor com sólidas concepções objetivistas e com práticas eminentemente transmissíveis provavelmente acabará utilizando as TDICs para complementar as aulas expositivas. Kenski (2012) complementa essa discussão sobre o uso tradicional das tecnologias na educação, em que, embora a tecnologia seja avançada, a forma como é utilizada, em muitos casos, é bem convencional, onde ocorre, por exemplo, em atividades assistidas pelo computador, definindo, assim, uma visão tradicionalista em que não se considera o aluno que aprende ou o contexto em que ocorre a educação.

Outros(as) licenciandos(as) conscientizam-se sobre a presença escassa das TDICs no contexto escolar, e no seu uso pelo corpo docente da escola: "Sua participação é muito pequena e muito particularizada, ficando na dependência de alguns poucos professores"(L14); "Eu não acredito que as TDICs estejam muito vinculadas à maior parte das escolas, atualmente"(L8). "Raramente são utilizadas em um contexto escolar em sala de aula" (L9); "Ainda são muito limitados as TDICs que chegam aos alunos e alunas das escolas públicas" (L16). Outro(a) afirmou que estavam mais presentes nas IES do que nas escolas de educação básica: "esses meios estão atualmente muito mais presentes no ensino superior do que nas escolas" (L1).

Kenski (2013) ressalta que as IES ainda vivenciam desafios para a incorporação dessas TDICs, tanto currículo quanto no processo de formação para seu uso no processo de ensino e aprendizagem. Com isso, os futuros professores não têm formação para integrar as tecnologias integradas ao ensino dos conteúdos em sala de aula, na educação básica. A respeito da incorporação das TDICs ser, ainda, pouco presente nas escolas, Coll et al (2010) concordam que, na maioria dos cenários de educação formal e escolar, as possibilidades de acesso e uso dessas tecnologias ainda são limitadas ou mesmo inexistentes.

No processo de avaliação, apenas três licenciandos(as) responderam associando as TDICs como formas criativas para avaliar, contudo, sem descrever como seria esse processo avaliativo: "elas servem como formas de agilidade e criatividade" (L5); "por meios padronizados de avaliar os resultados dos alunos" (L10); "pode também auxiliar em avaliar criando novas formas de medir o conhecimento" (L13). Um(a) licenciando(a), ainda, trata sobre os métodos tradicionais de avaliação ainda perpetuar nos diversos âmbitos educacionais: "acredito que, na sua maioria, ainda prevalece o uso tradicional de provas e trabalhos escritos" (L16).

Sobre esses métodos de ensino tradicionais, para Monereo e Pozo (2010) não basta fazer pequenos ajustes, colocar paliativos nas aulas e nos hábitos docentes, introduzindo computadores e alguma outra tecnologia para continuar desenvolvendo os mesmos currículos, e mesmas práticas de avaliação, necessitando, assim, de uma 
verdadeira reestruturação. Assim, a existência desses recursos tecnológicos e sua potencialidades na educação tornam-se fortemente contrastantes em função dos elementos ou ingredientes dos processos educacionais e instrucionais ainda existentes [Coll e Monereo 2010].

Dois licenciandos(as) afirmaram que não sabiam como responder à questão. Observa-se a necessidade de formação associadas ao conhecimento e domínio das TDICs, em que Coll e Illera (2010) associam à necessidade da alfabetização digital fazer parte do currículo escolar.

\subsection{Questionário de Autoavaliação}

Em relação ao questionário de autoavaliação, disponibilizado aos(às) licenciandos(as) após o término das aulas da disciplina, observa-se que eles adquiriram novos conhecimentos teóricos sobre as TDICs, refletindo mais criticamente sobre seu uso e sua integração no processo de ensino e aprendizagem dos conteúdos em sala de aula.

Quanto aos usos das TDICs no processo de ensino e aprendizagem, observa-se que obtiveram uma nova perspectiva e conseguiram associá-las aos conteúdos escolares, não descritivamente sobre como fariam essa integração, mas, com pretensões para esse uso em sala de aula, em sua prática docente: "Podem proporcionar ao ensino da Biologia vivências que transformam o aprendizado num processo mais rico $\mathrm{e}$ proveitoso" (L1); "Através de atividades a serem propostas aos alunos e também no desenvolvimento de aulas que possibilitem a integração dos alunos com conteúdos tecnológicos do seu cotidiano" (L5). Para Lima (2014), o trabalho com as TDICs centradas na ação do professor, apesar de ser o mais comumente utilizado, pode ser repensado para que esteja também centrado na ação do aluno, promovendo a construção do conhecimento a partir de seus conhecimentos prévios e de sua interação com a máquina diante dos erros e acertos cometidos. Dessa forma, o(a) licenciando(a) pode aprender a utilizar as TDICs, invertendo o método instrucionista, para centralizar esse uso ao aluno, o qual será o construtor e produtor do conhecimento.

$\mathrm{O}$ (a) licenciando(a) identificado como "L9" que no questionário de sondagem não associou as TDICs ao ensino, afirmando que raramente estavam presentes no contexto escolar, sugeriu utilizá-las em sua área de formação para abordar conteúdos específicos: "Na Biologia, uma forma de abordá-las é através da realidade aumentada, visto que elas podem explorar assuntos de difícil visualização" Diante disso, observa-se a necessidade da incorporação das TDICs no processo de formação inicial dos(as) licenciandos(as) para o potencial uso dessas tecnologias, integrando-as nos conteúdos escolares no processo de ensino e aprendizagem de sua futura profissão docente. Assim, a falta de uma formação qualificada do(a) licenciando(a) é um dos entraves para a promoção de um processo educacional que contribua para sua aprendizagem [Lima 2014].

Além de obterem uma perspectiva de uso das TDICs em conteúdos de sua área de formação, os(as) licenciandos(as) trouxeram em sua fala novos termos como planejamento, aprendizagem significativa, aprendizagem colaborativa e MADE: "Se direcionada com base em um planejamento cuidadosamente elaborado podem se tornar uma poderosa ferramenta na apresentação dos conteúdos de uma forma mais atrativa, tornando a aprendizagem mais significativa." (L15); "As TDICs farão parte da minha prática docente por meio do material autoral que produzirei e que utilizarei nas aulas" (L16); O(a) licenciando(a) identificada como "L3", que no questionário de sondagem 
afirmou que não saberia responder à questão proposta, trouxe a possibilidade de trabalhar os conteúdos sob uma perspectiva colaborativa e o uso de MADE: "Pretendo criar várias maneiras de trabalhar assuntos de forma mais colaborativa entre os alunos, por exemplo, utilizando uma rede social ou algum MADE na apresentação numa Feira de Ciências".

De acordo com Lima (2014) o que se aprende de forma significativa é a essência do conteúdo, sem a necessidade de memorização do material educacional tal e qual ele é apresentado. Sobre a criação desses MADE, com os atuais recursos digitais, os alunos podem aprender significativamente e passar a serem produtores de conteúdos que são a própria essência da interatividade que a tecnologia oferece [Monereo e Pozo 2010]. Assim, o papel do professor consiste em colocar as TDICs a serviço do aluno, criando um contexto de atividade que tenha como resultado sua aprendizagem e construção de conhecimento [Coll e Monereo 2010].

Um(a) licenciando(a) afirmou que não pretendia trabalhar com as TDICs dentro dos conteúdos na escola. Compreende-se através de Lima e Loureiro (2016) que os professores são (en)formados, seguindo um modelo fechado, pretensamente acabado e determinado em suas verdades. Assim, a tendência é que, em suas práticas no contexto escolar, esses profissionais prossigam perpetuando o modelo a que tiveram acesso durante a sua vida escolar e acadêmica, em um ciclo vicioso.

Outro(a) licenciando(a) possibilitou o uso das TDICs no ensino de alunos com deficiência: "As TDICs podem ser utilizadas para que alunos com deficiência auditiva/vocal tenham sua comunicação facilitada, principalmente entre os colegas em trabalho em grupo" (L7). Sobre essas possibilidades de uso com as TDICs, Coll et al (2010, p.75) afirmam que as TDICs, em algumas aplicações, têm uma série de características específicas que abrem novos horizontes e possibilidades para os processos de ensino e aprendizagem, e, são suscetíveis de gerar, "quando utilizadas em determinados contextos de uso, dinâmicas de inovação e aperfeiçoamento que seria impossível ou muito difícil conseguir sem ela".

\section{Considerações Finais}

Diante dos resultados obtidos na pesquisa, considera-se a necessidade de maior reflexão sobre o uso das TDICs durante o processo formativo, em como manejá-las e integrá-las no processo de formação inicial dos(as) licenciandos(as) para o processo de ensino e aprendizagem dos conteúdos a serem trabalhados em sala de aula, em sua futura profissão como docentes. Além disso, na integração das TDICs, nos processos de ensino e aprendizagem, o que o professorado deve aprender a dominar e a valorizar não é o novo instrumento, ou um novo sistema de representação do conhecimento, mas uma nova cultura de aprendizagem [Mauri e Onrubia 2010].

Ressalta-se a importância da incorporação das TDICs no currículo escolar e universitário, devido à necessidade em aprender a manejar e utilizar essas tecnologias de forma crítica e reflexiva, tirando o máximo proveito das possibilidades e potencialidades que elas oferecem, com a finalidade de preparar os alunos e futuros professores para viver na Sociedade da Informação, a qual é imprescindível ter um domínio dessas tecnologias, porquanto, em uma sociedade em que o principal bem de consumo é a informação, ser competente para gerenciá-la e transformá-la em conhecimento constitui-se em uma habilidade relevante para qualquer cidadão e, por 
conseguinte, deveria ocupar um lugar de honra nos currículos de qualquer nível educacional [Coll e Monereo 2010].

Apesar de a disciplina Tecnodocência trabalhar os conceitos teóricos e práticos sobre uso das TDICs, permaneceu a visão tradicionalista de ensino, centrada no professor como detentor das ferramentas digitais. Considera-se a necessidade de se trabalhar o uso e a integração dessas tecnologias desde o início do processo formativo dos cursos de Licenciatura na UFC e demais IES, para que o(a) licenciando(a) desprenda-se das visões de ensino e aprendizagem tradicionais. Lima (2014) traz contribuições a esse respeito com sua pesquisa com alunos de Ciências, ao verificar que apesar de alguns licenciandos criticarem o ensino centrado no professor, pautado na transmissão de informações e na memorização dos conteúdos científicos, nos planos de aula, apresentaram ações que enfatizaram as aulas expositivas e a transmissão dos conteúdos científicos. Para a autora, essas vinculações parecem estar bastante sedimentadas e requerem mais tempo e trabalho para serem transformadas.

\section{Referências}

Almeida, M. E. B. (2010) "Transformações no trabalho e na formação docente na educação a distância on-line”, Em Aberto, Brasília, v.23, n. 84, novembro.

Castells, M. (2000) 'La era de la información: la sociedade red. Madri, Alianza.

Coll, C.; Monereo, C. (2010) "Educação e aprendizagem no século XXI: novas ferramentas, novos cenários, novas finalidades". In: Psicologia da Educação Virtual: aprender e ensinar com as tecnologias da informação e da comunicação. Porto Alegre, Artmed, p.15-46.

Coll, C.; Mauri, T.; Onruba, J. (2010) "A incorporação das tecnologias da informação e comunicação na educação: do projeto técnico-pedagógico às práticas de uso”. In: Psicologia da Educação Virtual: aprender e ensinar com as tecnologias da informação e da comunicação. Porto Alegre, Artmed, p. 66-93.

Coll, C.; Illera, J. L. R. (2010) “Alfabetização, novas alfabetizações e alfabetização digital: as TIC no currículo escolar”. In: Psicologia da Educação Virtual: aprender e ensinar com as tecnologias da informação e da comunicação. Porto Alegre, Artmed, p.289-310.

Costa, F. A. (2010) "Do subaproveitamento do potencial pedagógico das TIC à desadequação da formação de professores e educadores". In: Colóquio Internacional Brasil-Portugal. São Paulo. Artmed.

Kenski, V. M. (2013), “Tecnologias e tempo docente”, São Paulo, Papirus.

Kenski, V. M. (2012), "Educação e tecnologia: o novo ritmo da informação", São Paulo, Papirus.

Lima, L. (2014) "Integração das tecnologias e currículo: a aprendizagem significativa de licenciandos de Ciências na apropriação e articulação entre saberes científicos, pedagógicos e das TDICs" Fortaleza. p.37.

Lima, L.; Loureiro, R. (2016). "Docência interdisciplinar nas licenciaturas por meio da integração às tecnologias digitais: o caso da tecnodocência", Revista Tecnologia e Sociedade, p. 122-138, Curitiba - PR. 
Monereo, C.; Pozo, J. I. (2010) "O aluno em ambientes virtuais: condições, perfil e competências". In: Psicologia da Educação Virtual: aprender e ensinar com as tecnologias da informação e da comunicação. Porto Alegre, Artmed, p. 97-117.

Mauri, T.; Onrubia, J. (2010) "O professor em ambientes virtuais: perfil, condições e competências". In: Psicologia da Educação Virtual: aprender e ensinar com as tecnologias da informação e da comunicação. Porto Alegre, Artmed, p. 118-135.

Mercado, L. P. L. (2014) "Formação e letramento digital de professores: memorial de um formador", Maceió, UFAL.

Ramos, F.; Linhares, R. N.; Batista, J. (2012) "TIC em educação: um contributo para definição do papel do professor". In: As redes sociais e seu impacto na cultura da educação do século XXI. Fortaleza, UFC.

Stake, R. (2005) “Investigación con estúdio de casos” Madri, Morata.

Tardif, M. (2002) “Saberes docentes e formação profissional”. Petrópolis, Vozes.

Yin, R. K. (2010) “Estudo de caso: planejamento e métodos” Porto Alegre, Bookman. 